\title{
El constructivismo y el construccionismo
}

\author{
Oscar Yecid Aparicio Gómez ${ }^{1}$ \\ Olga Lucía Ostos Ortiz ${ }^{2}$
}

Recibido: 30-07-2018

Aceptado: 28-09-2018

El estudio y la investigación sobre los procesos de construcción del conocimiento (Piaget, Vygotsky, Ausubel, Jonassen, Papert, entre otros) nos remiten a una reflexión sobre el constructivismo y su diversificación hacia otros modelos como el socio-constructivismo y el construccionismo. En el caso puntual de este último, la evolución del constructivismo al construccionismo representa también el paso del sujeto a la colectividad, de la persona a la comunidad. Por tanto, el constructivismo y el construccionismo están centrados en la persona ${ }^{3}$. Ampliando las consideraciones antropológicas de estos exponentes del constructivismo, considero importante resaltar que el concepto de "persona" en el que me enmarco es el que proponen Santo Tomás y Emmanuel Mounier ${ }^{5}$, la cual podría integrarse en una perspectiva constructivista.

\footnotetext{
1. Doctor en Filosofía (2006) y Doctor en Educación (2015). Profesor y Editor. Universidad de Barcelona, España.

Bogotá - Colombia.

Correo: oscar.yecid@gmail.com

ORCID: https://orcid.org/0000-0003-3535-6288

2. Docente investigador.

Bogotá - Colombia.

ORCID: https//orcid.org/0000-0002-6477-9872.

Google Académico: https://scholar.google.es/citations?user_yCBpLUsAAAAJ\&hl=es
}

3. Se elige el término persona ante otras consideraciones análogas, tales como individuo o sujeto, por la riqueza del término, desarrollada ampliamente en la historia del pensamiento y especialmente en la postguerra de mediados del siglo XX con el personalismo francés.

4. Tomás de Aquino define la persona como "aquella realidad que existe en sí y por sí, no en otra". (Tomás de Aquino, Suma Teológica, l, q.29, a.2.). En este sentido, afirma que persona es "lo más perfecto de toda la naturaleza, a saber, el ser subsistente en una naturaleza racional" (Tomás de Aquino, Suma Teológica, o.c., l, q.29, a.3). Santo Tomás afirma la superioridad ontológica de la persona sobre la realidad, así como su esencial unidad sustancial.

\footnotetext{
5. Para Emmanuel Mounier la persona es "[...] un ser espiritual constituido como tal por una forma de subsistencia y de independencia en su ser; mantiene esta subsistencia con su adhesión a una jerarquía de valores libremente adoptados, asimilados y vividos en un compromiso responsable y en una constante conversión; unifica así toda su actividad en la libertad y desarrolla por añadidura, a impulsos de actos creadores, la singularidad de su vocación" (Mounier, 1992: 625).
} 
El constructivismo (Anctil, Hass y Parkay, 2006) aboga por el pensamiento crítico, la prioridad del aprendizaje sobre la enseñanza, el empoderamiento de los aprendices como responsables de su propio proceso, y especialmente por el sentido que se otorga a la nueva información que se recibe permanentemente del entorno próximo y remoto. Igualmente, dirige su interés a la manera como se filtra, procesa o reactiva la información a partir de lo que ya se sabe para construir y reconstruir conocimiento, atribuirle significados, y para integrarla como propia y enraizarla en los conocimientos previos.

Podemos decir que Piaget (1980) describe un nuevo tipo de "humanismo" científico donde el aprendiz se inicia en los métodos de verificación y se consolida mediante un espíritu crítico y constructivo en medio de una cultura del devenir. Vygotsky (1995) coincide con él cuando reacciona a las prácticas educativas de tipo mecanicista que privilegiaban el conductismo como modelo que da prioridad a la interacción entre estímulos y respuestas, y expone que el aprendizaje real proviene de la interacción social y a la internalización o reconstrucción interna.

Piaget propone, según el modelo constructivista, que las experiencias previas de la persona constituyen la base de nuevas construcciones mentales en una relación directa con el objeto de conocimiento. La teoría de Piaget relata cómo los niños se desprenden progresivamente del mundo de los objetos concretos y contingencias locales, convirtiéndose poco a poco en personas capaces de manipular mentalmente objetos simbólicos en el ámbito de mundos hipotéticos y abstractos, tangibles e intangibles (Ackermann, 2001). Por su parte, Vygotsky amplía esta consideración cuando afirma que la construcción del conocimiento acontece a través de la interacción social con las demás personas, el entorno y la cultura. La coexistencia y complementariedad entre el constructivismo cognitivo $\left(\right.$ Piaget $\left.^{6}\right)$ y el constructivismo social $\left(V_{y g o t s k y}{ }^{7}\right.$ ) alimentará la reflexión posterior sobre la construcción del conocimiento.

Piaget y Vygostky destacan la actividad como origen del desarrollo cognitivo. Piaget, lo hace enfocado a la relación con el mundo material

6. Según Piaget (1980: 27) "[...] el factor principal de este constructivismo reside en un equilibrio mediante autorregulaciones que permite poner remedio a las incoherencias momentáneas, resolver los problemas y superar las crisis o los desequilibrios mediante una constante elaboración de estructuras nuevas que la escuela puede ignorar o favorecer según los métodos empleados".

7. Para (Vygotsky, 1995: 150) "Cualquier función en el desarrollo cultural del niño aparece dos veces, o en dos planos diferentes. En primer lugar, aparece en el plano social y después en el plano psicológico. En principio, aparece entre las personas como una categoría interpsicológica. Esto es igualmente cierto con respecto a la atención voluntaria, la memoria lógica, la formación de conceptos y el desarrollo de la voluntad". 
y Vygotsky lo hace privilegiando la interacción interpersonal a través de la razón, la afectividad y los instintos. Papert (1982) adapta el constructivismo de estos autores para que los aprendices en edad escolar accedan a fenómenos complejos a través de procesos simples mediados por lenguajes innovadores y procedimentales. Este es el caso del lenguaje de programación conocido como Logo, diseñado por Seymour Papert en 1968 y algunos de sus colaboradores. Logo fue concebido con la finalidad de usarlo para enseñar los conceptos básicos de la programación así como para presentar retos intelectuales a los niños para que puedan resolverse mediante un lenguaje de programación de tipo procedimental y recursivo, potenciador de la creatividad y la heurística (Aparicio, 2018). Cuando el niño revisa sus errores puede desarrollar sus habilidades metacognitivas, gracias a los procesos de revisión, autoevaluación, autocorrección y depuración.

Mitchel Resnick, influenciado, entre otros, por el lenguaje Logo, desarrolló en 2009, juntamente con el Grup Lifelong Kindergarten del MIT Media Lab de Massachusetts ${ }^{8}$, el lenguaje de programación Scratch que permite construir pequeños programas, historias y juegos informáticos, por medio del "encaje" de sentencias, órdenes y acciones, que hacen posible "imaginar, programar, compartir", investigar, experimentar y familiarizarse con la programación, mediante el uso de una sencilla interfaz gráfica que facilita el aprendizaje autónomo.

Papert (1982: 20) está de acuerdo con Piaget al afirmar que "el constructor necesita materiales para construir", pero disiente de él respecto al papel que atribuye a la cultura como fuente de estos materiales. Según Papert, la provisión de la materia prima por parte de la cultura puede ser abundante, insuficiente o nula para la construcción del conocimiento; no obstante, mientras Piaget describe mejor la génesis de la estabilidad mental interna en términos de sucesivas mesetas de equilibrio, Papert más está interesado en la dinámica del cambio (Ackermann, 2004).

Para Ackermann (2001) el construccionismo de Papert se centra en el arte de aprender, o aprender a aprender. Papert está interesado en cómo los estudiantes se involucran en una conversación (propia o ajena) con artefactos tangibles, y cómo estas conversaciones fomentan el aprendizaje autodirigido, para facilitar la construcción de nuevos conocimientos.

8. Véase: https://scratch.mit.edu/

9. Este es el lema de Scratch. 
Según Falbel (1993) el aprendizaje en el contexto constructivista es mucho mejor si los niños se comprometen en la construcción de un producto significativo.

El mismo Papert, junto con Harel, comenta que:

"El construccionismo -la palabra que se escribe con $\mathrm{n}$ en contraposición a la palabra que se escribe con v- tiene la misma connotación del constructivismo del aprendizaje como 'creación de estructuras de conocimiento', independientemente de las circunstancias del aprendizaje. Luego agrega la idea de que esto ocurre en forma especialmente oportuna en un contexto donde la persona que aprende está conscientemente dedicada a construir una entidad pública, ya sea un castillo de arena en la playa o una teoría del universo" (Papert y Harel, 1991: s.p.)

Papert (Ackermann, 2001) propone que la comprensión de la manera de hacer de los estudiantes permite conocer sus habilidades e identificar las herramientas cognitivas pertinentes para su propio proceso educativo, y según sus niveles de desarrollo. Para él, proyectar los sentimientos interiores y las ideas constituyen la clave para el aprendizaje. Por tanto, una de las grandes aportaciones del autor consiste en recordarnos que la inteligencia debe ser definida y estudiada in situ, en las situaciones biográficas reales del estudiante y su entorno próximo; de esta manera el conocimiento se construye activamente a través de contextualizar con su entorno, relacionarse con los demás, y desde la significatividad de sus relaciones al actuar con asertividad (Langer, 2016).

El aprendizaje construccionista implica a los estudiantes en su propio proceso educativo para que ellos mismos saquen sus propias conclusiones mediante la experimentación creativa y la elaboración de sus propios productos ${ }^{10}$. Por su parte, el maestro aparece como facilitador que actúa mediando entre el estudiante y su propio proceso (Pérez, 2013). El acompañamiento del maestro como facilitador hace que la enseñanza unidireccional decline a favor del asombro y satisfacción del estudiante ante sus propios descubrimientos como resultado de la construcción del conocimiento que ha alcanzado con la resolución de los problemas que él mismo ha planteado.

10. En este entorno entendemos por producto tanto la elaboración de un material tangible -"entidad pública" según Papert y Harel (1991: s.p.), cómo elaborar un informe, crear un juego con Scratch, hacer una conferencia, etc. 
Según Papert (Ackermann, 2004), el aprendizaje debe ser autodirigido, siguiendo un proceso iterativo para que los estudiantes puedan descubrir por sí mismos las mediaciones que mejor apoyen la exploración de su curiosidad. Indagar en lo desconocido, con los típicos episodios de desorientación, son cruciales en el aprendizaje. El desarrollo de los procesos educativos debería llevar a que cualquier persona pudiera aprender a aprender, obteniendo habilidades para el autoaprendizaje permanente y a lo largo de toda su vida, con las competencias básicas para valorar la información que requiere, y así estar facultado para asumir los retos que emergen en la sociedad del conocimiento (Ferreyra, 2014).

\section{Referencias bibliográficas}

Ackermann, E. (2001). Piaget's Constructivism, Papert's Constructionism: What's the difference? En Future of Learning Group Publication, 5(3). Recuperado de: http:// learning.media.mit.edu/content/publications/ EA.Piaget\%20_\%20Papert.pdf

Ackermann, E. (2004). Constructing knowledge and transforming the world. En Tokoro, M. y Steels, L. (Eds.). A learning zone of one's own: Sharing representations and flow in collaborative learning environments (pp. 15-37). Amsterdam: IOS Press.

Anctil, E. J., Hass, G. y Parkay, F.W. (2006). Teachers, public life, and curriculum reform. Curriculum planning -a contemporary approach (pp. 236-243). New York: Pearson Education, Inc.

Aparicio, O.Y. (2018). Las TIC como herramientas cognitivas. Revista Interamericana de Investigación, Educación y Pedagogía, RIIEP, 11(1). https://orcid.org/0000-0003-35356288

Falbel, A. (1993). Construccionismo. San José, Costa Rica: Fundación Omar Dengo, Programa de Informática Educativa MEP - FOD. Recuperado de: http://www.enlaces.cl/ portales/tp3197633a5s46/documentos/200707202307320.Taller_MicroMundos.pdf

Ferreyra, H. A. (2014). Mesas Socioeducativas para la Inclusión y la Igualdad. Un programa "De todos con todos". Una experiencia en construcción. Revista Interamericana de Investigación, Educación y Pedagogía, RIIEP, 7(2). DOI: https://doi. org/10.15332/s1657-107X.2014.0002.01

Langer, E. (2016). La construcción de confianza para el estudio de prácticas de resistencia en la escolarización de jóvenes en contextos de pobreza urbana. Revista Interamericana de Investigación, Educación y Pedagogía, RIIEP, 9(2). DOI: https://doi. org/10.22490/25391887.1945 
Mounier, E. (1992). Manifiesto al servicio del personalismo. En Obras Completas I. Salamanca: Sígueme.

Papert, S. (1982). Desafío a la mente: Computadoras y educación. Buenos Aires: Galápago.

Papert, S. y Harel, I. (1991). Situating Constructionism. En Constructionism. Norwood, NJ: Ablex Publishing Corporation. Recuperado de: http://www.papert.org/articles/ SituatingConstructionism.html

Piaget, J. (1980). Psicología y pedagogía. Barcelona: Ariel.

Tomás de Aquino, santo. (1960). Suma Teológica. Madrid: BAC.

Pérez, T. H. P. (2013). Aproximaciones al estado de la cuestión de la investigación en educación y derechos humanos. Revista Interamericana de Investigación, Educación y Pedagogía, RIIEP, 6(1). DOI: https://doi.org/10.15332/s1657-107X.2013.0001.05

Vygotsky, L. S. (1995). Pensamiento y lenguaje. Buenos Aires: Ediciones Fausto. 